\title{
Systematic video analysis of $A C L$ injuries in professional male football (soccer): injury mechanisms, situational patterns and biomechanics study on 134 consecutive cases
}

\author{
Francesco Della Villa (1) , ${ }^{1}$ Matthew Buckthorpe, ${ }^{1}$ Alberto Grassi, ${ }^{2}$ Alberto Nabiuzzi, \\ Filippo Tosarelli, ${ }^{1}$ Stefano Zaffagnini, ${ }^{2}$ Stefano Della Villa ${ }^{1}$
}

\begin{abstract}
- Additional material is published online only. To view please visit the journal online (http://dx.doi.org/10.1136/ bjsports-2019-101247)
\end{abstract}

${ }^{1}$ Education and Research Department, Isokinetic Medical Group, FIFA Medical Centre of Excellence, Bologna, Italy ${ }^{2}$ lla Clinica Ortopedica e Traumatologica, Istituto Ortopedico Rizzoli Istituto di Ricovero e Cura a Carattere Scientifico, Bologna, EmiliaRomagna, Italy

Correspondence to Dr Francesco Della Villa, Education and Research Department, Isokinetic Medica Group, FIFA Medical Centre of Excellence, Bologna, Italy; f.dellavilla@isokinetic.com

Accepted 4 May 2020 Published Online First 19 June 2020
ABSTRACT

Background A few small studies have reported on the mechanisms of $A C L$ injury in professional male football. Aim To describe the mechanisms, situational patterns and biomechanics (kinematics) of $\mathrm{ACL}$ injuries in professional male football matches.

Methods We identified 148 consecutive ACL injuries across 10 seasons of professional Italian football. 134 (90\%) injury videos were analysed for mechanism and situational pattern, while biomechanical analysis was possible in 107 cases. Three independent reviewers evaluated each video. ACL injury epidemiology (month), timing within the match and pitch location at the time of injury were also reported.

Results 59 (44\%) injuries were non-contact, 59 (44\%) were indirect contact and $16(12 \%)$ were direct contact. Players were frequently perturbed immediately prior to injury. We identified four main situational patterns for players who suffered a non-contact or an indirect contact injury: (1) pressing and tackling $(n=55)$; (2) tackled $(n=24) ;(3)$ regaining balance after kicking $(n=19)$; and (4) landing from a jump ( $n=8)$. Knee valgus loading ( $n=83,81 \%$ ) was the dominant injury pattern across all four of these situational patterns $(86 \%, 86 \%, 67 \%$ and $50 \%$, respectively). $62 \%$ of the injuries occurred in the first half of the matches $(p<0.01)$. Injuries peaked at the beginning of the season (September-October) and were also higher at the end of the season (March-May). Conclusions $88 \%$ of $A C L$ injuries occurred without direct knee contact, but indirect contact injuries were as frequent as non-contact injuries, underlying the importance of mechanical perturbation. The most common situational patterns were pressing, being tackled and kicking.

\section{INTRODUCTION}

ACL injury is a severe and concerning health issue among professional football players that causes long lay-off time. ${ }^{1}$ Despite improved knowledge on ACL injuries and injury prevention, the rate of injuries in professional football is not declining. ${ }^{1}$ Each team of 25 players can expect one ACL injury every 2 years. $^{2}$ Even if $95 \%-100 \%$ of professional footballers return to play (RTP), ${ }^{13}$ the risk of subsequent knee injury, ${ }^{4}$ early onset of knee osteoarthritis ${ }^{6}$ and reduced career length ${ }^{78}$ are serious concerns.

Understanding the situations and mechanisms which lead to ACL injuries is crucial to effectively design specific exercise programmes to reduce their incidence. Several systematic video analysis studies of ACL injuries have been published across different sports. ${ }^{9-16}$ With regard to football, three additional studies have been published in the past 5 years. ${ }^{17-19}$ However, limitations in the study design, such as lack of systematic assessment ${ }^{19}$ and the limited number of cases with more than 30\% dropout rate ${ }^{18}$ could not provide conclusive evidence on the mechanisms of ACL injury in football.

In addition, there are gaps which need to be systematically addressed. First is the lack of focus on the perturbation type injury, which is found to be important in American football. ${ }^{11}$ Second is the lack of research detailing the biomechanical factors of ACL injuries in football, particularly concerning the role of the trunk. Finally, there is little research detailing the distribution of ACL injuries across the season, as well as within the match and on the pitch location.

As such, the purpose of this study was to describe on a large cohort of professional football players the mechanisms, situational patterns and biomechanics related to ACL injury. A further purpose was to document the distribution of ACL injuries across the match, season and pitch location.

\section{METHODS}

Injury identification and video extraction

A systematic search of online database resources was performed across 10 seasons (from 2008/2009 to $2018 / 2019$, until December 2018) to identify ACL injuries occurring during matches in players of Italian first (Serie A) and second (Serie B) division professional football teams.

To identify ACL injuries, each season and team rosters were extracted from online databases (legaseriea.it; legab.it) and single team websites. Then, each player was searched on Transfermarkt.de (Transfermarkt, Hamburg, Germany) for details on injury history. This methodology has been recently validated for identification of injuries in professional football ${ }^{20}$ and was also adopted by two very recent studies on RTP after ACL injury ${ }^{8}$ and hip surgery ${ }^{21}$ in professional football.

Second, the same systematic single-player approach was used in additional data sources to look for other possible injuries which may have been missed, including national (eg, www.gazzetta. it; www.corrieredellosport.it) and local media. 
Finally, injuries were included only when we were able to track an official communication with the medical staff of the team stating the nature of the injury (complete ACL injury) suffered by the player. Through similar methods (public available sources), ACL reconstructions underwent by all players were also tracked.

Videos of matches were obtained from an online digital platform (wyscout.com; Wyscout, Genova, Italy) ( $n=127)$. When the video was not available, a second digital platform was searched (paninidigital.com; Panini Digital, Digital Soccer Project, Modena, Italy) $(\mathrm{n}=7)$. Videos were then processed on a digital cloud (paninidigitalcloud.com) and downloaded to a personal computer.

Match video processing was done with a cloud available tool (Digital Log, Digital Soccer Project). Each video of ACL injury was cut to approximately $12-15 \mathrm{~s}$ prior to and $3-5 \mathrm{~s}$ post the estimated injury frame (IF) in order to accurately evaluate the playing situation that preceded the injury and the mechanism of injury.

\section{Video evaluation}

The videos were independently evaluated by three different reviewers (FDV, AG, MB) according to two predetermined checklists (online supplementary table 1 and table 2). All reviewers are involved in sports medicine and orthopaedic rehabilitation practice (MD, MD and PhD).

Each video of ACL injury was downloaded on the personal computer and opened with an available software online, Kinovea (KinoveaInk), and analysed through an evaluation flow.

Each reviewer evaluated the original video to define the injurious situation, defensive or offensive, which was then categorised based on ball possession and specific playing situation. Then, a series of views were used to determine the injury mechanism and situational pattern (see table 1 for explanation of the terms). Three categories of injury mechanism were used: (1) non-contact, defined as an injury occurring without any contact (at the knee or any other level) prior to or at IF; (2) indirect contact, defined as an injury resulting from an external force applied to the footballer, but not directly to the injured knee; and (3) direct contact, defined as an external force directly applied to the injured knee. ${ }^{22}$ Situational patterning was done only in cases of non-contact or indirect contact mechanisms. Based on previous findings we considered the estimation of IF as initial contact (IC) plus $40 \mathrm{~ms}^{12} 23$

Subsequently, the reviewers met for a 2-day comprehensive discussion about the main injury mechanism and situational patterns. If no complete agreement was reached between reviewers, problems were solved with a collegiate decision, as in previous research. ${ }^{14} 18$ Consensus agreement on all the items, including IC and IF, was reached during the meeting. Prior to the meeting, the intraclass correlation index for the IC between the reviewers was 0.99 .

\section{Biomechanical analysis (kinematics)}

Biomechanical/kinematic analysis was performed on non-contact and indirect contact injuries when a frontal and/or sagittal view of sufficient quality was available. The analysis was performed to estimate intersegmental relationship and joint angles according to frontal and sagittal plane alignment at IC and IF. When more than one view was available, composite videos were created by manual synchronisation using visual clues (eg, initial ground contact). ${ }^{14}$ Three videos had five camera views, 10 had four, 54 had three, 48 had two and 19 had one.

Sagittal plane angles were estimated using a custom-made software (GPEM Screen Editor, GPEM, Genova, Italy) to the nearest $5^{\circ}$ at IC and estimated IF.

Trunk tilt was also estimated to the nearest $5^{\circ}$ on the frontal plane at IC and IF, while the remaining frontal and coronal plane estimated joint positions were categorised according to the appearance at IC and IF.

Foot strike was evaluated according to a previous methodology ${ }^{18}$ and after foot contact to the ground at IC and IF. The items that have been evaluated are listed in online supplementary table 2 .

\section{Seasonal, match and field distribution}

For each available injury video, a list of data regarding the seasonal, match and field distribution were gathered through systematic web revision and analysis of videos in relation to the position of the injured player. We considered (1) month of ACL injury, (2) phase of the game when the ACL injury occurred (minute and half), (3) number of minutes played by the ACLinjured athlete and (4) field location according to a customised version of an already published division of the pitch. ${ }^{22}$ Player localisation at the time of ACL injury was gathered according to the field lines. The football pitch was divided as indicated in online supplementary table 1 and further divided into 11 different zones. The field zone dimensions in square metres were calculated considering the official FIFA football field size (105 by $70 \mathrm{~m}$ ) (see online supplementary material).

\section{Patient and public involvement}

The results of the study will be shared with publicly available resources (eg, newspaper) to inform the audience with regard to treatment for ACL injuries.

\section{Equity, diversity and inclusion}

Football is played by millions of women around the world, and the British Journal of Sports Medicine encourages research that includes gender-based analysis. The methodology that we used was not applicable to women's football. Alternative approaches should be used to fill this gap and our group is going towards this direction.

Table 1 Terms, definitions and their use within this manuscript to describe ACL injuries in football (valid for team sports)

\begin{tabular}{ll}
\hline Term & Definition and use \\
\hline Injury mechanism & $\begin{array}{l}\text { This term describes the ACL injury causation, referring to player-to-player interaction that led to the injury. Three categories have been used: (1) non- } \\
\text { contact, (2) indirect contact and (3) direct contact. }\end{array}$ \\
Situational pattern & $\begin{array}{l}\text { This term describes the situation leading to ACL injuries. The patterns can be divided into defensive and offensive situations. This is the situation and } \\
\text { not just the action, in that it considers the action interacting with the environment (eg, pressing pattern). }\end{array}$ \\
\hline $\begin{array}{l}\text { Biomechanics of injury } \\
\text { This term refers to the kinematics or intersegmental body segment relationships at initial contact and suspected injury frame on the frontal and } \\
\text { sagittal planes. }\end{array}$
\end{tabular}




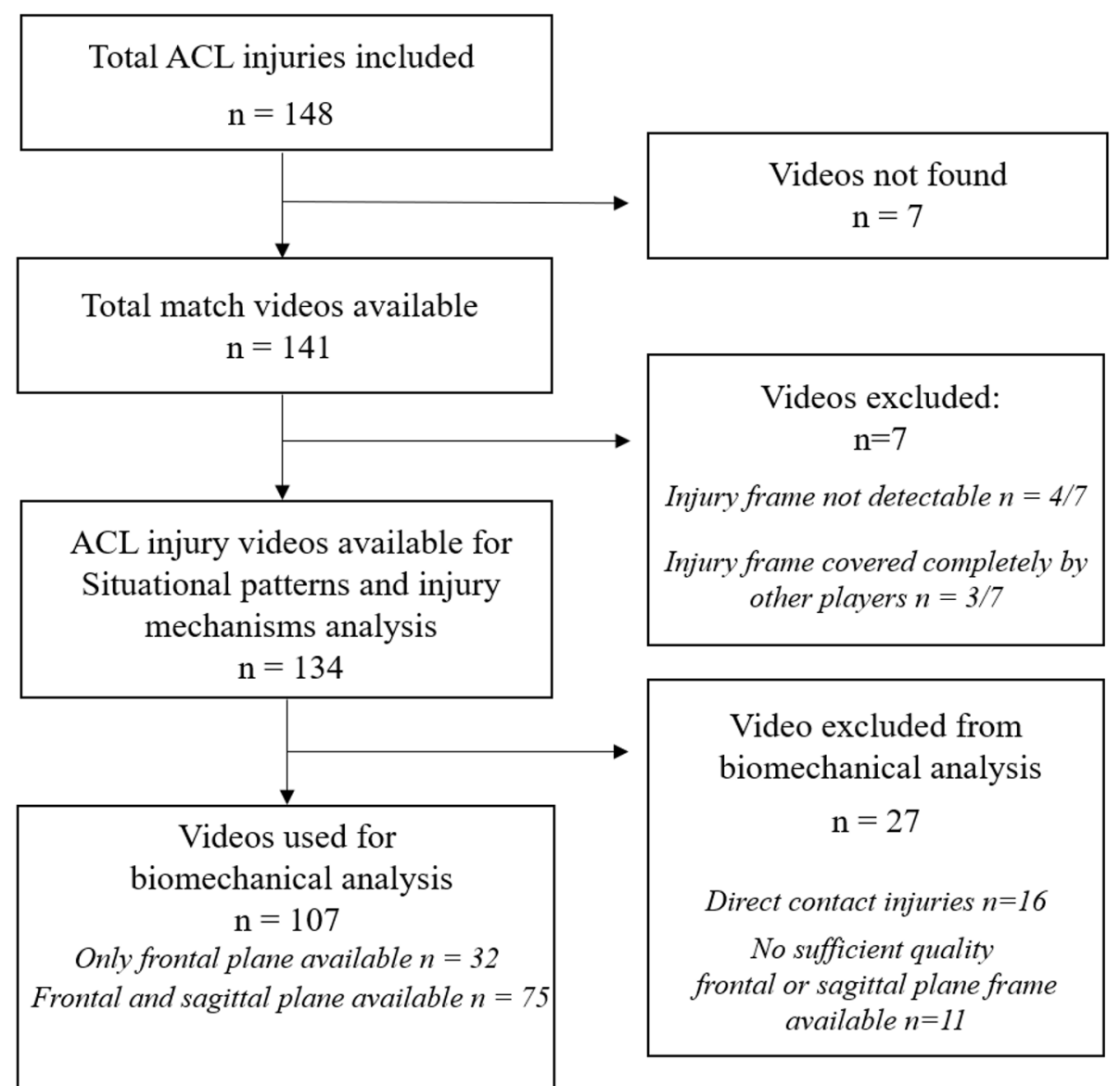

Figure 1 Detailed flow chart of the study.

\section{Ethical considerations}

All the videos we accessed are publicly available, data were treated confidentially, no personal player information was accessed and therefore ethical permission was not required. ${ }^{14}$

\section{Statistical analysis}

Continuous variables are presented as mean $( \pm S D)$ or median (range) as appropriate according to the distribution of variables. Discrete variables were presented as absolute numbers and as percentage of the total number of observations. The proportion test was used to explore possible differences in the distribution of ACL injuries between match halves. An a priori statistically significant level of $\mathrm{p}<0.05$ was used. Microsoft Excel 2016 (Microsoft, USA) and Stata V.12 were used for analyses.

\section{RESULTS}

One hundred and forty-eight ACL injuries were tracked and included. Of these, 75 and 55 occurred during the Serie B and A matches, while 10, 6 and 2 injuries occurred during international, Italian cup and friendly competitions, respectively. There were $89(60 \%)$ injuries to the right and 58 (39\%) injuries to the left ACL (1 injury was unidentifiable), with 128 primary, 9 contralateral native and 11 previously reconstructed knee (ACL graft injuries) ACL injuries.

\section{Injury mechanism analysis}

Video footage was available and identifiable for situational pattern and injury mechanism analysis in 134 cases (90\%). Detailed study flow is presented in figure 1. Most injuries (121 cases; 90\%) involved loading of the injured leg, with single limb loading on the ground frequently observed (94 cases; $70 \%)$. We categorised $59(44 \%)$ non-contact, 59 (44\%) indirect contact and $16(12 \%)$ direct contact injuries (see table 2 for injury mechanism analysis).

\section{Direct contact injuries}

Direct contact injuries $(n=16)$ occurred in both defensive $(n=9)$ and offensive $(\mathrm{n}=7)$ playing situations, with five injuries being classified as tackling, eight tackled and three goalkeeping injuries.

Biomechanically most of the direct contact ACL injuries resulted from an external force with a knee valgus loading $(n=13)$, combined with a posterolateral force application in one case, while the remaining three cases were hyperextension injuries, as a direct consequence of an anteriorly applied force.

\section{Situational pattern of indirect and non-contact injuries}

Four main situational patterns were identified for non-contact or indirect contact ACL injuries:

- Pressing/tackling $(\mathrm{n}=55)$.

- Tackled $(\mathrm{n}=24)$.

- Regaining balance after kicking $(\mathrm{n}=19)$.

- Landing from a jump $(\mathrm{n}=8)$.

Finally, the other 12 cases did not fall into one of the aforementioned categories. Additional details are reported in table 3.

Pressing and tackling injuries (47\%) were all classified as defensive, where the player typically approached the opponent with the intention to tackle. In pressing, the player was injured during non-contact deceleration or cutting. In tackling injuries, there was typically opponent contact prior to or at estimated IF (figure 2). 


\begin{tabular}{|c|c|}
\hline Variables & Results \\
\hline \multicolumn{2}{|l|}{ Weather conditions } \\
\hline \multirow[t]{2}{*}{ Precipitations } & Yes $(n=6)$ \\
\hline & No $(n=128)$ \\
\hline \multirow[t]{3}{*}{ Sunny weather } & Yes $(n=51)$ \\
\hline & No $(n=34)$ \\
\hline & Night $(n=49)$ \\
\hline \multirow[t]{2}{*}{ Playing phase before injury } & Defensive $(n=91)$ \\
\hline & Offensive $(n=43)$ \\
\hline \multicolumn{2}{|l|}{ Field location at injury } \\
\hline \multirow[t]{3}{*}{ Long axis of the field } & Defensive third $(n=50)$ \\
\hline & Mid-field third $(n=45)$ \\
\hline & Offensive third ( $\mathrm{n}=39$ ) \\
\hline \multirow[t]{3}{*}{ Short axis of the field } & Left side corridor $(n=33)$ \\
\hline & Middle corridor $(n=67)$ \\
\hline & Right side corridor $(n=34)$ \\
\hline \multirow[t]{2}{*}{ Player contact preceding injury } & Yes $(n=56)$ \\
\hline & No $(n=78)$ \\
\hline \multirow[t]{4}{*}{ If contact, where? } & Upper body $(n=41)$ \\
\hline & Pelvis $(n=6)$ \\
\hline & Injured leg $(n=2)$ \\
\hline & Uninjured leg $(n=7)$ \\
\hline \multirow[t]{3}{*}{ Player contact at IF } & Direct contact $(n=16)$ \\
\hline & Indirect contact $(\mathrm{n}=31)$ \\
\hline & Non-contact $(\mathrm{n}=87)$ \\
\hline \multirow[t]{4}{*}{ If indirect contact at IF, where? } & Upper body $(n=20)$ \\
\hline & Pelvis $(n=6)$ \\
\hline & Injured leg (ankle) (n=1) \\
\hline & Uninjured leg $(n=4)$ \\
\hline \multirow[t]{3}{*}{ Injury classification } & Direct contact $(n=16)$ \\
\hline & Indirect contact $(\mathrm{n}=59)$ \\
\hline & Non-contact $(n=59)$ \\
\hline \multirow[t]{3}{*}{ How many feet on the ground } & One $(n=94)$ \\
\hline & Two $(n=29)$ \\
\hline & Unsure $(n=10)$ \\
\hline \multirow[t]{3}{*}{ Leg loading at IF } & Injured leg ( $n=121)$ \\
\hline & Uninjured leg ( $n=2)$ \\
\hline & Unsure $(n=10)$ \\
\hline \multirow[t]{3}{*}{ Horizontal speed } & Zero $(n=6)$ \\
\hline & Low $(n=49)$ \\
\hline & High $(n=78)$ \\
\hline \multirow[t]{3}{*}{ Vertical speed } & Zero $(n=75)$ \\
\hline & Low $(n=49)$ \\
\hline & High $(n=9)$ \\
\hline
\end{tabular}

IF, injury frame.

Being 'tackled', the second most common situation (20\%), involved a duel-type interaction between the opponent and the injured player (figure 3$)$ either in $(n=13,54 \%)$ or out $(n=11$, $46 \%$ ) of ball possession. There was typically a mechanical perturbation involving the upper $(n=14)$ or lower $(n=10)$ part of the body, without direct knee contact.

Regaining balance after kicking (16\%) also involved player-toplayer contact $(\mathrm{n}=11,58 \%)$, mostly to the upper body.

Landing from a jump (7\%) was less prevalent, with six cases from heading and two in goalkeepers when landing after catching the ball. Five of these occurred during single leg landing and three during double leg landing.
Table 3 Indirect contact and non-contact injuries' situational pattern classification

\begin{tabular}{ll}
\hline Categories & ACL injuries \\
\hline Pressing/tackling & Total, $\mathrm{n}=55(47 \%)$ \\
& Pressing, $\mathrm{n}=40$ \\
& Tackling, $\mathrm{n}=15$ \\
\hline Tackled & Total, $\mathrm{n}=24(20 \%)$ \\
& Lower body, $\mathrm{n}=9$ \\
& Upper body, $\mathrm{n}=15$ \\
Regaining balance after kicking & Total, $\mathrm{n}=19(16 \%)$ \\
\hline Landing from a jump & Total, $\mathrm{n}=8$ (7\%) \\
& Heading, $\mathrm{n}=6$ \\
& Goalkeepers, $\mathrm{n}=2$ \\
\hline Others & Total, $\mathrm{n}=12(10 \%)$ \\
& Dribbling, $\mathrm{n}=2$ \\
& Cutting without the ball, $\mathrm{n}=2$ \\
& Jumping take-off, $\mathrm{n}=2$ \\
& Receiving the ball, $\mathrm{n}=2$ \\
& Controlling the ball with chest, $\mathrm{n}=1$ \\
& Regaining balance after reaching, $\mathrm{n}=1$ \\
& Kicking the ground, $\mathrm{n}=1$ \\
& Goalkeeping (side stepping), $\mathrm{n}=1$ \\
\hline
\end{tabular}

\section{Biomechanical analysis}

Biomechanical analysis was possible in 107 cases, with 75 cases having both frontal and sagittal plane images and 32 with frontal plane only. More variability in intersegmental body positioning was observed at IC, rather than at IF. All angle data are reported as median values. On the sagittal plane at IC, players displayed an upright trunk $\left(0^{\circ}\right)$, early flexed hip $\left(35^{\circ}\right)$, shallow knee flexion $\left(17.5^{\circ}\right)$ and early plantar flexed ankle with heel strike in nearly half (48\%) of the cases. On the frontal plane at IC, the trunk was slightly tilted ipsilaterally $\left(5^{\circ}\right)$ either in a neutral position $(34 \%)$ or rotated towards the uninjured limb (53\%), an abducted hip $(88 \%)$, neutral (63\%) or valgus (27\%) knee appearance, and an externally rotated foot $(59 \%)$.

From a sagittal plane perspective at estimated IF, the trunk remained upright $\left(0^{\circ}\right)$, with similar hip flexion $\left(37.5^{\circ}\right)$, greater knee flexion $\left(40^{\circ}\right)$ and neutral ankle $\left(0^{\circ}\right)$, with planted flat foot $(89 \%)$. On the frontal plane, the trunk remained tilted ipsilaterally $\left(5^{\circ}\right)$, with greater prevalence of trunk rotation towards the uninjured side (83\%). The hip remained abducted in most cases $(72 \%)$, with greater prevalence of knee valgus $(81 \%)$ and externally rotated foot $(66 \%)$. The most frequent intersegmental positioning at IF is reported in figure 4.

Knee valgus loading was frequently observed $(81 \%)$, and a significant increase in hip internal rotation and/or adduction from IC to IF was seen in most (69\%), while valgus collapse was uncommon (13\%). Additional details are reported in tables 4 and 5 .

\section{Seasonal, match and field distribution}

Seasonal distribution $(\mathrm{n}=148)$ demonstrated bimodal distribution, with more injuries early in the season (September-October) and a secondary peak later in the season (March-May) (figure 5).

More injuries occurred during the first $(\mathrm{n}=88,62 \%)$ than the second $(\mathrm{n}=53,38 \%)$ half $(\mathrm{p}<0.01)$. A quarter of all injuries $(\mathrm{n}=34)$ happened in the first $15 \mathrm{~min}$ of the match (figure 6A). When considering the minutes played, correcting for substitutions, $68 \%$ of ACL injuries happened in the first $45 \mathrm{~min}$ (figure 6B). 

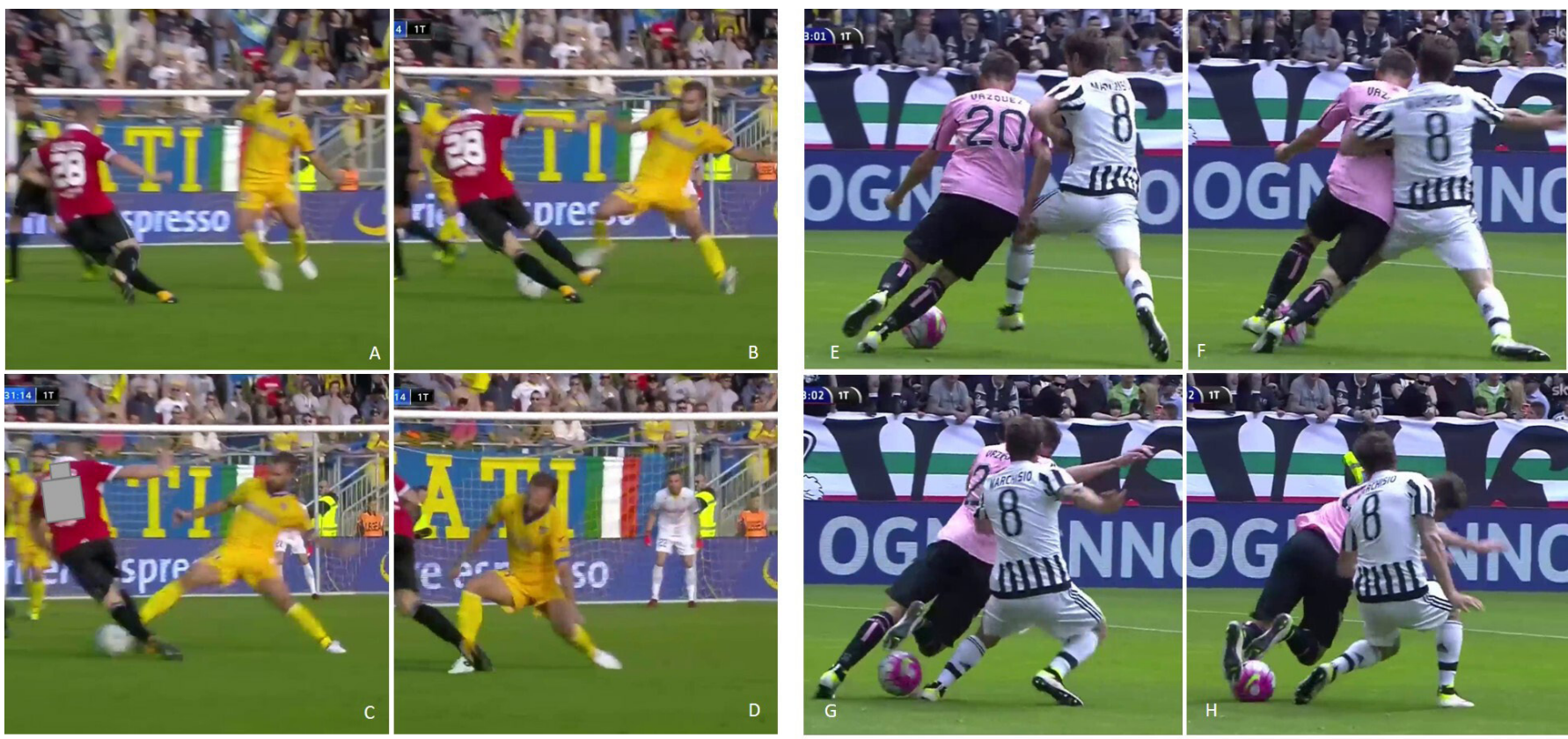

Figure 2 Pressing and tackling injuries. Pressing: approaching the opponent (A), initial contact (B), injury frame (C) and loss of balance (D). Tackling: approaching the opponent $(E)$, initial contact and tackling $(F)$, injury frame $(G)$ and loss of balance $(H)$.

Injuries according to pitch location $(n=133)$ are detailed in online supplementary material.

\section{DISCUSSION}

The most important findings of the present study are that (1) most ACL injuries in professional male football occur without direct contact mechanism at IF, but a large proportion occur by some form of indirect contact; (2) four main situational patterns were identified, with an under-representation of the heading mechanism; and (3) the distribution during the match and the season suggests a higher risk in the first part of both.

Injury mechanisms

Of the injuries, $88 \%$ occurred without direct knee contact, similar to another study (85\%). ${ }^{18}$ However, $44 \%$ of ACL injuries were due to indirect contact (predominantly at the upper body or pelvis level), meaning that $56 \%$ of injuries actually involved some form of contact, leaving only $44 \%$ non-contact injuries.
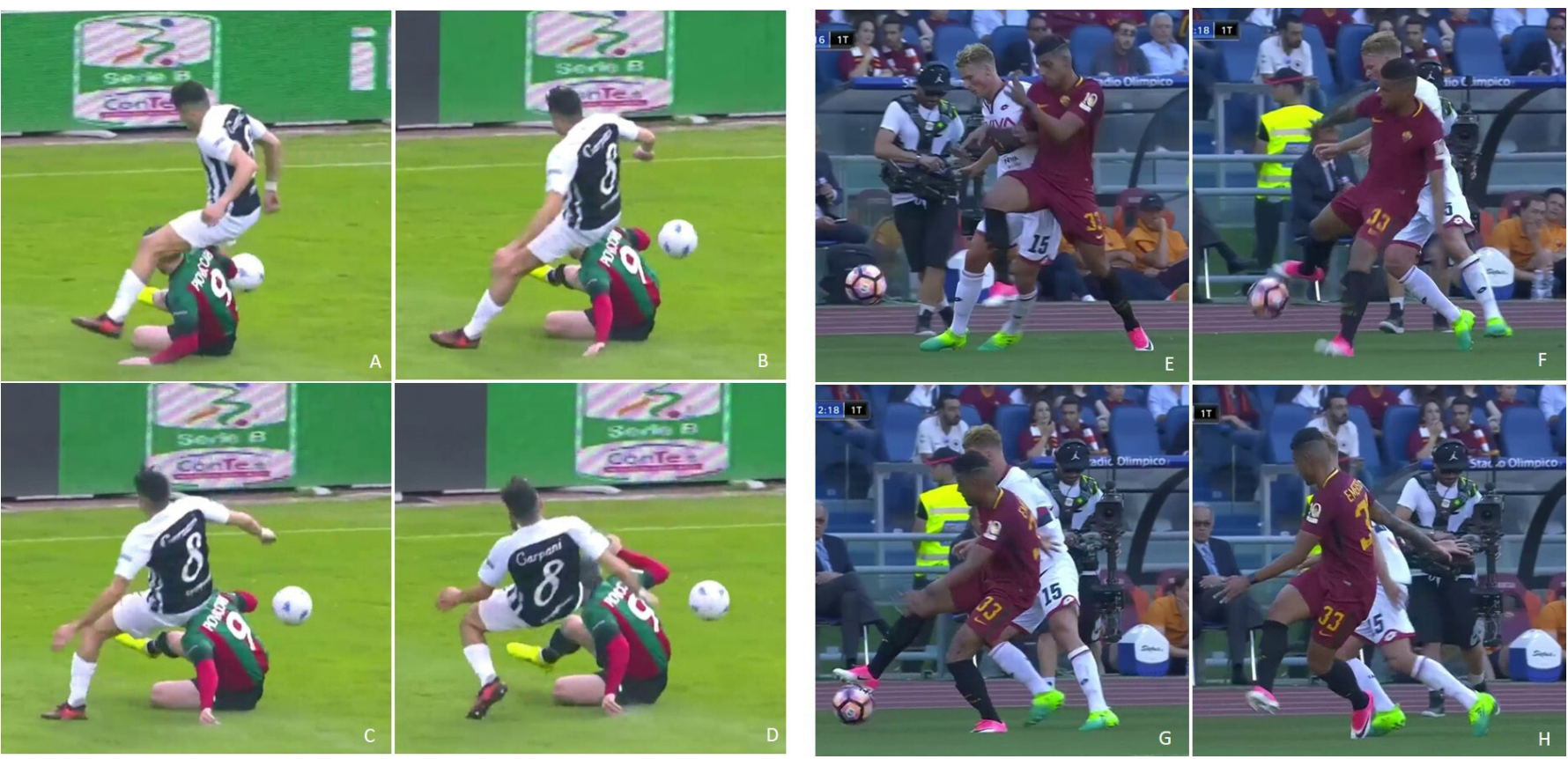

Figure 3 Being tackled situational patterns. Example of injury categorised as 'being tackled' with contact on lower body part (uninjured limb): mechanical perturbation (A), initial contact (B), injury frame (C) and loss of balance (D). Being tackled on the upper part of the body: mechanical perturbation $(E)$, initial contact $(F)$, estimated $A C L$ injury frame $(G)$ and loss of balance $(H)$. 


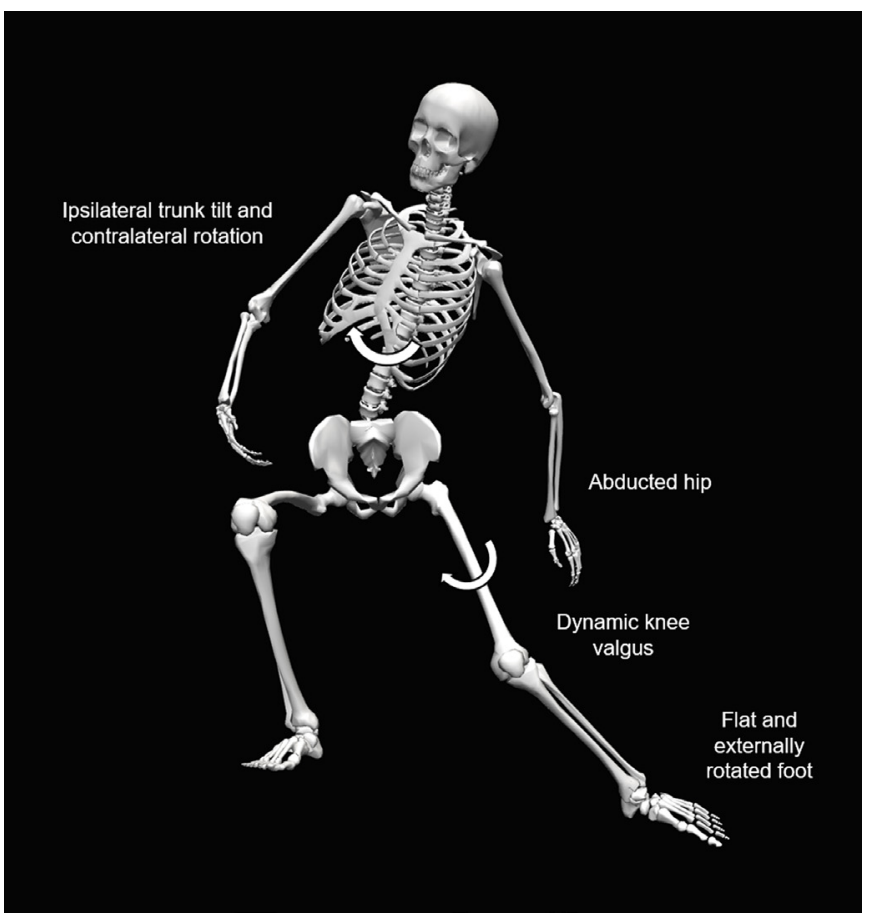

Figure 4 Frequently observed mechanism for non-contact $\mathrm{ACL}$ injuries during pressing situation.

Although different from Waldén et al (66\% non-contact), ${ }^{18}$ this is identical to others (56\% direct and indirect injuries). ${ }^{17} 19$ Given our study has adopted the largest prospectively identified video analysis sample to date $(\mathrm{N}=134$ injuries), these findings are important and likely reflect the generalised ACL injury mechanisms in professional footballers.

Situational pattern of non-contact and indirect injuries Similar to others, two-thirds of ACL injuries involved defending, ${ }^{1718}$ while pressing or attempting to tackle.

We identified four key situational patterns, three previously described $^{18}$ (although with different prevalence): (1) pressing/ tackling; (2) regaining balance after kicking; (3) landing from a jump; and (4) a new situational pattern, 'tackled', accounting for $20 \%$ of all non-contact or indirect contact injuries. Contact mostly occurred prior to the injury, predominantly to the upper body. This mechanical perturbation, often coupled with a distraction immediately prior to injury, played an important role in the causation of these injuries in our cohort, and has been shown to be important in other sports, such as basketball ${ }^{13}$ and rugby, ${ }^{14}$ and more recently American football in which 'perturbation like scenarios' account for half of ACL injuries. ${ }^{11}$ Landing from heading was under-represented in our cohort versus another $(7 \%$ vs $25 \%),{ }^{18}$ which may reflect differences in playing style ${ }^{24}$ and/or anthropometrics.

\section{Biomechanics}

Our data support the existing literature showing ACL injuries occur generally in early knee flexion, with dynamic knee valgus loading. ${ }^{101213151823}$ We reported a high knee loading movement pattern (knee dominant), with limited loading/motion at joints other than the knee, similar to other research. ${ }^{18}{ }^{23}$ From IC to IF, no change in sagittal plane angles at other joints than the

\begin{tabular}{|c|c|c|c|c|c|c|}
\hline Variables & Total & Pressing & Tackled & Kicking & Landing & Other \\
\hline $\begin{array}{l}\text { Trunk flexion IC } \\
\text { (+ flexion, - extension) }\end{array}$ & $0(-35,70)$ & $-5(-35,40)$ & $5(-20,70)$ & $-5(-20,30)$ & $-2.5(-15,5)$ & $0(0,20)$ \\
\hline $\begin{array}{l}\text { Trunk flexion IF } \\
\text { (+ flexion, - extension) }\end{array}$ & $0(-40,90)$ & $-5(-35,50)$ & $5(-40,90)$ & $0(-10,50)$ & $0(-25,10)$ & $5(0,40)$ \\
\hline $\begin{array}{l}\text { Hip flexion IC } \\
\text { (+ flexion, - extension) }\end{array}$ & $35(0,90)$ & $40(5,60)$ & $37.5(25,90)$ & $30(0,60)$ & $17.5(10,30)$ & $45(10,60)$ \\
\hline $\begin{array}{l}\text { Hip flexion IF } \\
\text { (+ flexion, - extension) }\end{array}$ & $37.5(0,90)$ & $42.5(5,80)$ & $30(10,90)$ & $30(0,90)$ & $17.5(5,45)$ & $45(10,60)$ \\
\hline $\begin{array}{l}\text { Knee flexion IC } \\
\text { (+ flexion, - extension) }\end{array}$ & $17.5(-5,90)$ & $15(5,90)$ & $20(0,60)$ & $20(-5,40)$ & $12.5(10,15)$ & $15(10,35)$ \\
\hline $\begin{array}{l}\text { Knee flexion IF } \\
\text { (+ flexion, - extension) }\end{array}$ & $40(-50,120)$ & $40(-35,120)$ & $60(-50,80)$ & $35(-35,60)$ & $30(10,55)$ & $45(10,55)$ \\
\hline $\begin{array}{l}\text { Ankle flexion IC } \\
\text { (+ dorsiflexion, - plantar flexion) }\end{array}$ & $-10(-55,45)$ & $-15(-30,15)$ & $-5(-30,45)$ & $-15(-55,15)$ & $-5(-45,0)$ & $-10(-25,0)$ \\
\hline $\begin{array}{l}\text { Ankle flexion IF } \\
\text { (+ dorsiflexion, - plantar flexion) }\end{array}$ & $0(-40,45)$ & $-10(-40,20)$ & $15(-30,45)$ & $0(-40,25)$ & $10(10,20)$ & $10(0,15)$ \\
\hline Foot strike at IC & & & & & & \\
\hline Heel & $51(48 \%)$ & $29(57 \%)$ & $15(68 \%)$ & $5(31 \%)$ & $0(0 \%)$ & $2(22 \%)$ \\
\hline Flat & $30(28 \%)$ & $15(30 \%)$ & $3(14 \%)$ & $7(44 \%)$ & $2(25 \%)$ & $3(33 \%)$ \\
\hline Toe & $15(14 \%)$ & $3(6 \%)$ & $2(9 \%)$ & $4(25 \%)$ & $5(62.5 \%)$ & $1(11 \%)$ \\
\hline Unsure & $10(9 \%)$ & $4(8 \%)$ & $2(9 \%)$ & $0(0 \%)$ & $1(12.5 \%)$ & $3(33 \%)$ \\
\hline Foot strike at IF & & & & & & \\
\hline Heel & $0(0 \%)$ & $0(0 \%)$ & $0(0 \%)$ & $0(0 \%)$ & $0(0 \%)$ & $0(0 \%)$ \\
\hline Flat & $94(89 \%)$ & $45(88 \%)$ & $20(91 \%)$ & $16(100 \%)$ & $6(75 \%)$ & $7(78 \%)$ \\
\hline Toe & $2(2 \%)$ & $2(4 \%)$ & $0(0 \%)$ & $0(0 \%)$ & $0(0 \%)$ & $0(0 \%)$ \\
\hline Unsure & $10(9 \%)$ & $4(8 \%)$ & $2(9 \%)$ & $0(0 \%)$ & $2(25 \%)$ & $2(22 \%)$ \\
\hline
\end{tabular}


Table 5 Frontal and transverse plane metrics of non-contact or indirect contact ACL injuries, stratified according to main situational patterns (data on 107 cases)

\begin{tabular}{|c|c|c|c|c|c|c|}
\hline Variables & Total & Pressing & Tackled & Kicking & Landing & Other \\
\hline $\begin{array}{l}\text { Trunk tilt IC } \\
\text { (+ ipsilateral, - contralateral) }\end{array}$ & $5(-35,35)$ & $10(-5,30)$ & $10(-10,20)$ & $0(-35,30)$ & $7.5(-5,35)$ & $-2.5(-15,20)$ \\
\hline $\begin{array}{l}\text { Trunk tilt IF } \\
\text { (+ ipsilateral, - contralateral) }\end{array}$ & $5(-20,50)$ & $17.5(-5,90)$ & $10(-15,35)$ & $0(-20,50)$ & $0(-15,40)$ & $-2.5(-15,10)$ \\
\hline \multicolumn{7}{|l|}{ Trunk rotation IC } \\
\hline Towards injured & $6(6 \%)$ & $4(8 \%)$ & $1(4 \%)$ & $1(7 \%)$ & $0(0 \%)$ & $0(0 \%)$ \\
\hline Neutral & $35(34 \%)$ & $14(28 \%)$ & $7(32 \%)$ & $6(40 \%)$ & $2(25 \%)$ & $6(75 \%)$ \\
\hline Towards uninjured & $55(53 \%)$ & $28(56 \%)$ & $11(50 \%)$ & $8(53 \%)$ & $6(75 \%)$ & $2(25 \%)$ \\
\hline Unsure & $7(7 \%)$ & $4(8 \%)$ & $3(14 \%)$ & $0(0 \%)$ & $0(0 \%)$ & $0(0 \%)$ \\
\hline \multicolumn{7}{|l|}{ Trunk rotation IF } \\
\hline Towards injured & $5(5 \%)$ & $4(8 \%)$ & $1(4,3)$ & $0(0 \%)$ & $0(0 \%)$ & $0(0 \%)$ \\
\hline Neutral & $8(8 \%)$ & $2(4 \%)$ & $1(4,3 \%)$ & $3(20 \%)$ & $1(12.5 \%)$ & $1(12.5 \%)$ \\
\hline Towards uninjured & $86(83 \%)$ & $40(80 \%)$ & $20(87 \%)$ & $12(80 \%)$ & $7(87.5 \%)$ & $7(87.5 \%)$ \\
\hline Unsure & $5(5 \%)$ & $4(8 \%)$ & $1(4,3 \%)$ & $0(0 \%)$ & $0(0 \%)$ & $0(0 \%)$ \\
\hline \multicolumn{7}{|l|}{ Frontal plane hip alignment IC } \\
\hline Abduction & $91(88 \%)$ & $46(92 \%)$ & $18(82 \%)$ & $13(87 \%)$ & $7(87.5 \%)$ & $7(87.5 \%)$ \\
\hline Neutral & $7(7 \%)$ & $2(4 \%)$ & $2(9 \%)$ & $1(7 \%)$ & $1(12.5 \%)$ & $1(12.5 \%)$ \\
\hline Adduction & $0(0 \%)$ & $0(0 \%)$ & $0(0 \%)$ & $0(0 \%)$ & $0(0 \%)$ & $0(0 \%)$ \\
\hline Unsure & $5(5 \%)$ & $2(4 \%)$ & $2(9 \%)$ & $1(7 \%)$ & $0(0 \%)$ & $0(0 \%)$ \\
\hline \multicolumn{7}{|l|}{ Frontal plane hip alignment IF } \\
\hline Abduction & $74(72 \%)$ & $39(78 \%)$ & $15(68 \%)$ & $11(73 \%)$ & $6(75 \%)$ & $3(37.5 \%)$ \\
\hline Neutral & $15(15 \%)$ & $5(10 \%)$ & $2(9 \%)$ & $3(20 \%)$ & $2(25 \%)$ & $3(37.5 \%)$ \\
\hline Adduction & $8(8 \%)$ & $3(6 \%)$ & $3(14 \%)$ & $0(0 \%)$ & $0(0 \%)$ & $2(25 \%)$ \\
\hline Unsure & $6(6 \%)$ & $3(6 \%)$ & $2(9 \%)$ & $1(7 \%)$ & $0(0 \%)$ & $0(0 \%)$ \\
\hline \multicolumn{7}{|l|}{ Frontal plane knee alignment IC } \\
\hline Valgus & $28(27 \%)$ & $13(26 \%)$ & $8(35 \%)$ & $3(20 \%)$ & $2(25 \%)$ & $2(25 \%)$ \\
\hline Neutral & $66(63 \%)$ & $32(64 \%)$ & $12(52 \%)$ & $10(67 \%)$ & $6(75 \%)$ & $6(75 \%)$ \\
\hline Varus & $2(2 \%)$ & $0(0 \%)$ & $1(4 \%)$ & $1(7 \%)$ & $0(0 \%)$ & $0(0 \%)$ \\
\hline Unsure & $8(8 \%)$ & $5(10 \%)$ & $2(9 \%)$ & $1(7 \%)$ & $0(0 \%)$ & $0(0 \%)$ \\
\hline \multicolumn{7}{|l|}{ Frontal plane knee alignment IF } \\
\hline Valgus & $83(81 \%)$ & $43(86 \%)$ & $19(86.4 \%)$ & $10(67 \%)$ & $4(50 \%)$ & $7(87.5 \%)$ \\
\hline Neutral & $9(9 \%)$ & $3(6 \%)$ & $1(4.5 \%)$ & $2(13 \%)$ & $3(37.5 \%)$ & $0(0 \%)$ \\
\hline Varus & $4(4 \%)$ & $1(2 \%)$ & $1(4.5 \%)$ & $1(7 \%)$ & $1(12.5 \%)$ & $0(0 \%)$ \\
\hline Unsure & $7(7 \%)$ & $3(6 \%)$ & $1(4.5 \%)$ & $2(13 \%)$ & $0(0 \%)$ & $1(12.5 \%)$ \\
\hline \multicolumn{7}{|l|}{ Foot position IC } \\
\hline External & $61(59 \%)$ & $30(60 \%)$ & $13(59 \%)$ & $11(73 \%)$ & $2(25 \%)$ & $5(62.5 \%)$ \\
\hline Neutral & $18(17 \%)$ & $11(22 \%)$ & $2(9 \%)$ & $1(7 \%)$ & $4(50 \%)$ & $0(0 \%)$ \\
\hline Internal & $5(5 \%)$ & $1(2 \%)$ & $2(9 \%)$ & $1(7 \%)$ & $0(0 \%)$ & $1(12.5 \%)$ \\
\hline Unsure & $19(18 \%)$ & $8(16 \%)$ & $5(23 \%)$ & $2(13 \%)$ & $2(25 \%)$ & $2(25 \%)$ \\
\hline \multicolumn{7}{|l|}{ Foot position IF } \\
\hline External & $68(66 \%)$ & $34(68 \%)$ & $15(68 \%)$ & $11(73 \%)$ & $4(50 \%)$ & $4(50 \%)$ \\
\hline Neutral & $10(10 \%)$ & $7(14 \%)$ & $0(0 \%)$ & $1(7 \%)$ & $2(25 \%)$ & $0(0 \%)$ \\
\hline Internal & $6(6 \%)$ & $2(4 \%)$ & $2(9 \%)$ & $1(7 \%)$ & $1(0 \%)$ & $1(12.5 \%)$ \\
\hline Unsure & $19(18 \%)$ & $7(14 \%)$ & $5(23 \%)$ & $2(13 \%)$ & $2(25 \%)$ & $3(37.5 \%)$ \\
\hline \multicolumn{7}{|c|}{ Significant hip IR/ADD from IC to IF? } \\
\hline Yes & $71(69 \%)$ & $36(72 \%)$ & $16(73 \%)$ & $10(67 \%)$ & $3(37.5 \%)$ & $6(75 \%)$ \\
\hline No & $20(19 \%)$ & $6(12 \%)$ & $4(18 \%)$ & $3(20 \%)$ & $5(62.5 \%)$ & $2(25 \%)$ \\
\hline Unsure & $12(12 \%)$ & $8(16 \%)$ & $2(9 \%)$ & $2(13 \%)$ & $0(0 \%)$ & $0(0 \%)$ \\
\hline \multicolumn{7}{|l|}{ Valgus collapse? } \\
\hline Yes & $13(13 \%)$ & $7(14 \%)$ & $4(18 \%)$ & $1(7 \%)$ & $0(0 \%)$ & $1(12.5 \%)$ \\
\hline No & $86(83 \%)$ & $41(82 \%)$ & $18(82 \%)$ & $13(87 \%)$ & $7(87.5 \%)$ & $7(87.5 \%)$ \\
\hline Unsure & $4(4 \%)$ & $2(4 \%)$ & $0(0 \%)$ & $1(7 \%)$ & $1(12.5 \%)$ & $0(0 \%)$ \\
\hline
\end{tabular}

Four injuries had incomplete biomechanical data on the frontal plane.

$A D D$, adduction; IC, initial contact; IF, injury frame; IR, internal rotation. 


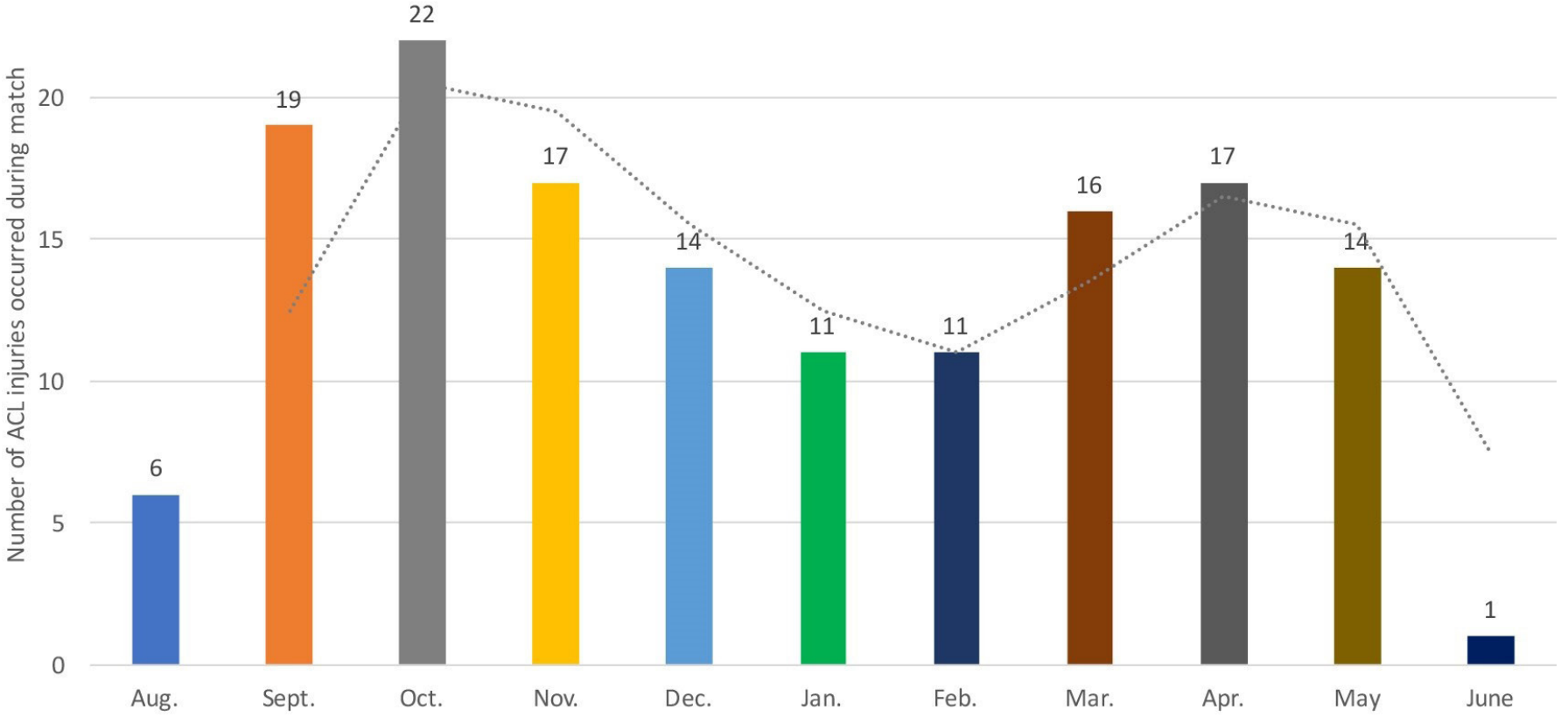

Figure 5 Distribution of $A C L$ injuries throughout the football season $(n=148)$. Bimodal distribution is noted. The dotted line is the moving average of $\mathrm{ACL}$ injuries per month.

knee occurred, with an average $22.5^{\circ}$ increase in knee flexion. This is similar to Waldén et $a l^{18}$ although we reported higher knee flexion angles at IF $\left(40^{\circ}\right.$ vs $\left.30^{\circ}\right)$, and in almost perfect agreement with Koga et al, who found near identical increases in knee flexion from IC to estimated IF frame $40 \mathrm{~ms}$ later $\left(+24^{\circ}\right)$, using the model-based image-matching technique. ${ }^{12}$ ACL injuries typically occur with around three to four times body mass $(2000-3000 \mathrm{~N})$ vertically directed ground reaction force. ${ }^{12}$ In this sagittal plane scenario, these forces would likely be preferentially focused on the knee, predisposing it to injury.

This preferential knee loading strategy was accompanied by altered frontal and transverse plane motions, thought to be essential in ACL injury. ${ }^{25}$ Knee valgus and valgus-type loading from IC to IF were found, similar to what previous authors have found. ${ }^{18} 23$ Similarly, hip abduction motion was common, ${ }^{18} 23$ with a significant increase in hip internal rotation and/or adduction (medial thigh motion) from IC to IF in most (69\%) cases. This common increase in frontal plane motion is likely due to the high external knee abduction moment, determined by hip abduction $^{26} 27$ on a laterally orientated and planted foot position outside the base of support. ${ }^{26} 28$ Although we observed an average ipsilateral trunk tilt in the frontal plane for all ACL injuries $\left(5^{\circ}\right.$ at IC and IF), this appears more important for pressingtype ACL injuries, where we found a $10^{\circ}$ ipsilateral trunk lean at IC, increasing to $17.5^{\circ}$ at IF. A lateral trunk lean may increase ACL loading as a result of a lateral shift in centre mass, achieving a resultant vector line lateral to the knee joint and causing a knee abduction moment. ${ }^{27}$

\section{Seasonal, match and field distribution}

The higher proportion of ACL injuries occurring during the first part of the season (September-October) and the secondary peak (March-May) compared with the winter months (JanuaryFebruary) is similar to other research. ${ }^{19}$ This is likely indicative of sunny/hot weather and hard/dry fields, which are thought to increase risk of injury. ${ }^{29} 30$ Similar to previous findings
(95\%-97\%), ${ }^{18} 19$ most injuries occurred without rain (96\%). Rain is more apparent in late autumn and winter months in Italy. This seasonal injury pattern could also relate to a lack of preparedness at the start of season and cumulative fatigue at the end of the season. Additionally, higher exposure during these months cannot be excluded.

The higher prevalence of ACL injuries in the first half suggests accumulating fatigue throughout the match is not a key risk factor for injury. ${ }^{3132}$ It is likely that factors other than fatigue may be more relevant to ACL injuries, which are more specific to the first half. These may include differences in playing actions, particularly intense engagements in the opening period of the match. ${ }^{33}$ The fact that a quarter of ACL injuries happen in the first 15 min of match may also suggest an inadequate neuromuscular readiness of fresh, unfatigued players.

The field distribution of ACL injuries is consistent with the higher proportion of defensive injuries ${ }^{17}$ and shows a higher proportion of injuries on the wings, similar to another study. ${ }^{19}$ This is likely due to a higher proportion of duels and deceleration-type tasks occurring in these areas.

\section{Methodological considerations}

The main strengths of our study are (1) its sample size, which is the largest to date in a systematic video analysis study of ACL injuries; (2) the consecutive nature of the 134 injuries analysed; (3) the consistent biomechanical analysis of three independent viewers using measurement tools; and (4) the presentation of field, match and seasonal distribution data, which have never been presented before in a consecutive series. The weaknesses of the study lie in the methodology used to identify ACL injuries, different from the gold standard of prospective studies with frequent contact with the teams, and the use of video analysis with assessment of kinematics using videos and tools, as opposed to the gold standard model-based image-matching technique. ${ }^{34}$ However, the video analysis method is valid ${ }^{34}$ and consistently adopted in 


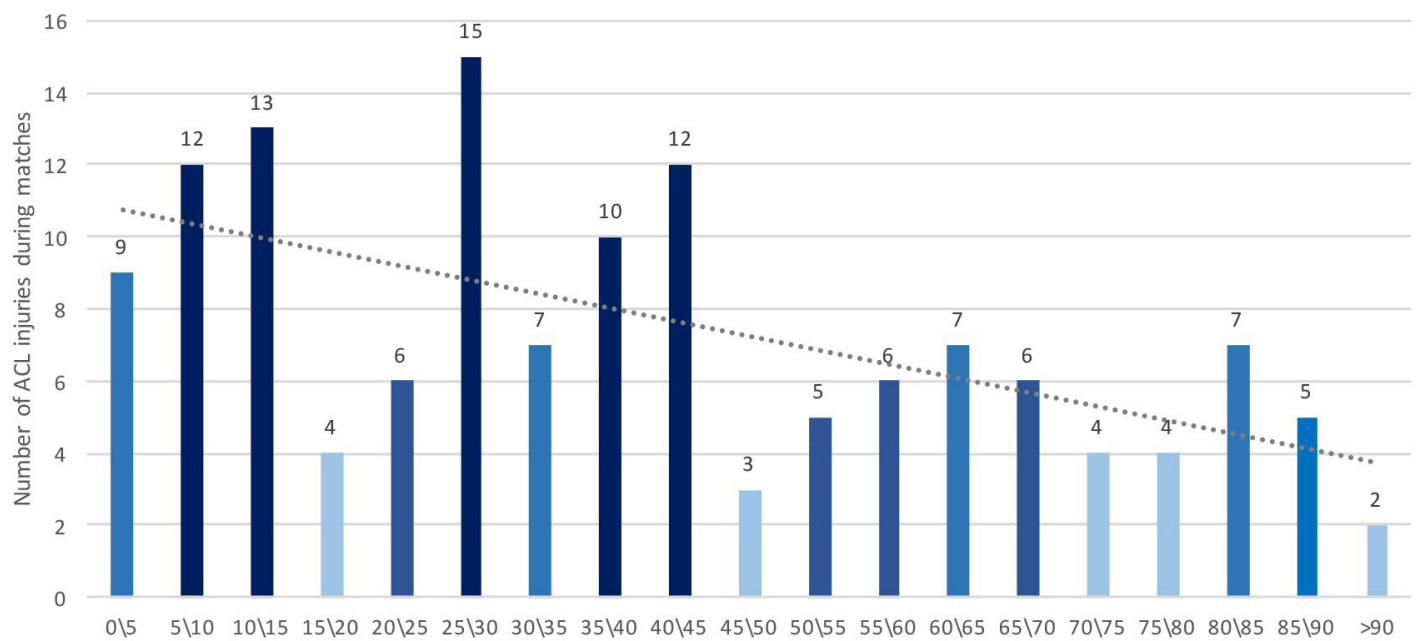

Minutes zones during the football match

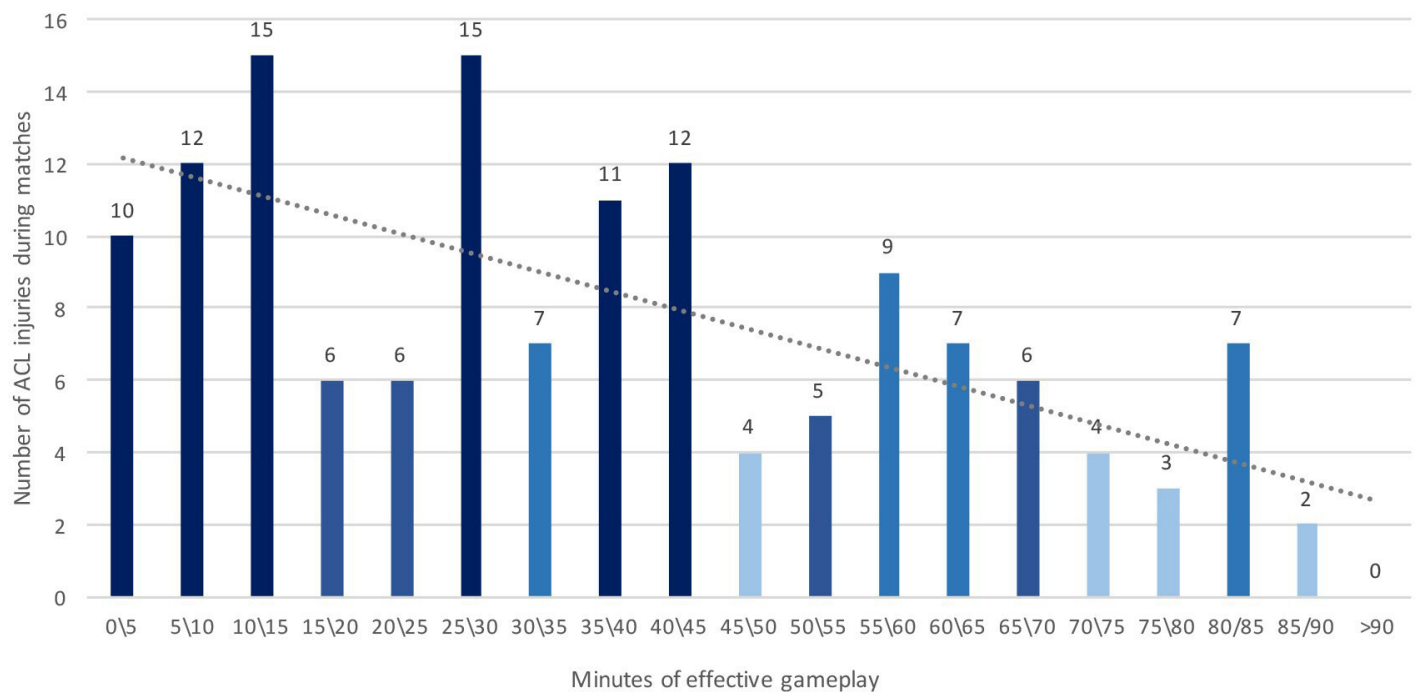

Figure 6 Distribution of ACL injuries throughout the match. A decrease in the number of ACL injuries is noted across the game. Dotted lines represents the linear tendencies of distribution of ACL injury during the match $(A)$ and according to effective playing time (B).

\section{What are the findings?}

- Indirect contact injuries are equally as prevalent as noncontact injuries in professional Italian male football.

- Four main situational patterns were present: (1) pressing/ tackling, (2) tackled, (3) regaining balance after kicking and (4) landing from a jump.

- $\mathrm{ACL}$ injuries from landing after heading are underrepresented in Italian professional male footballers.

- ACL injuries are more prevalent at the start of the match (first half) than at the end of the match (second half).

\section{How might it impact on clinical practice in the future?}

- There is a need for a greater focus on indirect contact ACL injuries and the role of perturbation in prevention and rehabilitation after $\mathrm{ACL}$ injury.

- Fatigue over the course of match play appears not to be a major risk factor for $\mathrm{ACL}$ injuries in professional male football. many previously studies. ${ }^{9-11} 13-19$ An additional limitation of our study was the exclusion of training injuries, which could potentially interfere with the overall presentation of ACL injuries in professional football.

\section{CONCLUSIONS}

Most ACL injuries occur without direct knee contact in professional football, but nearly half occur via indirect contact mechanisms. While the defensive 'pressing/tackling' type was the most common situational pattern observed, we also described the offensive or duel 'tackled' situation. This information may be useful for a better comprehension of potential situations that may be considered in primary reduction and secondary reduction (rehabilitation) setting.

Twitter Francesco Della Villa @fdellavilla

Acknowledgements The authors thank Dr Ing Stefano Di Paolo for helping with figure 4. The authors also thank Dr Federico Ferri and Sky Sport Italia for the kind collaboration in providing the access and permission to use of figure 2 and figure 3 frames.

Contributors FDV, MB and AG contributed to the ideation of the study. AN and FT supported the data collection. FDV, MB and AG undertook the video analysis. FDV, 
$M B, A G, A N, F T, S Z$ and SDV provided intellectual contribution to the writing and drafting of the manuscript.

Funding The authors have not declared a specific grant for this research from any funding agency in the public, commercial or not-for-profit sectors.

Competing interests None declared.

Patient consent for publication Not required.

Ethics approval All the videos we accessed are publicly available, data were treated confidentially, and no personal player information was accessed, and therefore ethical permission was not required. Injured players' privacy was respected and no personal information has been published.

Provenance and peer review Not commissioned; externally peer reviewed.

Data availability statement All data relevant to the study are included in the article or uploaded as supplementary information.

\section{ORCID iD}

Francesco Della Villa http://orcid.org/0000-0001-9379-6666

\section{REFERENCES}

1 Waldén $\mathrm{M}$, Hägglund M, Magnusson $\mathrm{H}$, et al. ACL injuries in men's professional football: a 15 -year prospective study on time trends and return-to-play rates reveals only $65 \%$ of players still play at the top level 3 years after ACL rupture. Br I Sports Med 2016;50:744-50

2 Grassi A, Macchiarola L, Filippini M, et al. Epidemiology of anterior cruciate ligament injury in Italian first division soccer players. Sports Health 2020;12:279-88.

3 Zaffagnini S, Grassi A, Marcheggiani Muccioli GM, et al. Return to sport after anterior cruciate ligament reconstruction in professional soccer players. Knee 2014;21:731-5.

4 Brophy RH, Schmitz L, Wright RW, et al. Return to play and future ACL injury risk after ACL reconstruction in soccer athletes from the multicenter orthopaedic outcomes network (moon) group. Am J Sports Med 2012;40:2517-22.

5 Wiggins AJ, Grandhi RK, Schneider DK, et al. Risk of secondary injury in younger athletes after anterior cruciate ligament reconstruction: a systematic review and meta-analysis. Am J Sports Med 2016;44:1861-76.

6 von Porat A, Roos EM, Roos H. High prevalence of osteoarthritis 14 years after an anterior cruciate ligament tear in male soccer players: a study of radiographic and patient relevant outcomes. Ann Rheum Dis 2004;63:269-73.

7 Arundale AJH, Silvers-Granelli HJ, Snyder-Mackler L. Career length and injury incidence after anterior cruciate ligament reconstruction in major League soccer players. Orthop J Sports Med 2018:6:232596711775082.

8 Niederer D, Engeroff T, Wilke J, et al. Return to play, performance, and career duration after anterior cruciate ligament rupture: a case-control study in the five biggest football nations in Europe. Scand J Med Sci Sports 2018;28:2226-33.

9 Bere T, Mok K-M, Koga H, et al. Kinematics of anterior cruciate ligament ruptures in world cup alpine skiing: 2 case reports of the slip-catch mechanism. Am I Sports Med 2013:41:1067-73.

10 Cochrane JL, Lloyd DG, Buttfield A, et al. Characteristics of anterior cruciate ligament injuries in Australian football. J Sci Med Sport 2007;10:96-104.

11 Johnston JT, Mandelbaum BR, Schub D, et al. Video analysis of anterior cruciate ligament tears in professional American football athletes. Am I Sports Med 2018:46:862-8.

12 Koga H, Nakamae A, Shima Y, et al. Mechanisms for noncontact anterior cruciate ligament injuries: knee joint kinematics in 10 injury situations from female team handball and basketball. Am J Sports Med 2010;38:2218-25.
13 Krosshaug T, Nakamae A, Boden BP, et al. Mechanisms of anterior cruciate ligament injury in basketball: video analysis of 39 cases. Am J Sports Med 2007;35:359-7.

14 Montgomery C, Blackburn J, Withers D, et al. Mechanisms of ACL injury in professional rugby Union: a systematic video analysis of 36 cases. Br J Sports Med 2018;52:994-1001

15 Olsen O-E, Myklebust G, Engebretsen L, et al. Injury mechanisms for anterior cruciate ligament injuries in team handball: a systematic video analysis. Am J Sports Med 2004:32:1002-12.

16 Stuelcken MC, Mellifont DB, Gorman AD, et al. Mechanisms of anterior cruciate ligament injuries in elite women's netball: a systematic video analysis. J Sports $\mathrm{SCi}$ 2016;34:1516-22.

17 Brophy RH, Stepan JG, Silvers HJ, et al. Defending puts the anterior cruciate ligament at risk during soccer: a gender-based analysis. Sports Health 2015;7:244-9.

18 Waldén M, Krosshaug T, Bjørneboe J, et al. Three distinct mechanisms predominate in non-contact anterior cruciate ligament injuries in male professional football players: a systematic video analysis of 39 cases. Br J Sports Med 2015;49:1452-60.

19 Grassi A, Smiley SP, Roberti di Sarsina T, et al. Mechanisms and situations of anterior cruciate ligament injuries in professional male soccer players: a YouTube-based video analysis. Eur J Orthop Surg Traumatol 2017:27:967-81.

20 Leventer L, Eek F, Hofstetter S, et al. Injury patterns among elite football players: a media-based analysis over 6 seasons with emphasis on playing position. Int I Sports Med 2016:37:898-908.

21 Locks R, Utsunomiya $H$, Briggs KK, et al. Return to play after hip arthroscopic surgery for femoroacetabular impingement in professional soccer players. Am I Sports Med 2018:46:273-9.

22 Marshall SW, Padua D, McGrath M. Incidence of ACL injury. In: Hewett TE, Schultz SJ, Griffin LY, eds. Understanding and preventing noncontact $A C L$ injuries. 1st Edn. American Orthopaedic Society for Sports Medicine, 2007: 5-29.

23 Koga H, Nakamae A, Shima Y, et al. Hip and ankle kinematics in noncontact anterior cruciate ligament injury situations: video analysis using model-based image matching. Am J Sports Med 2018;46:333-40.

24 Andersen TE, Tenga A, Engebretsen L, et al. Video analysis of injuries and incidents in Norwegian professional football. Br J Sports Med 2004;38:626-31.

25 McLean SG, Huang X, Su A, et al. Sagittal plane biomechanics cannot injure the ACL during sidestep cutting. Clin Biomech 2004;19:828-38.

26 Dempsey AR, Lloyd DG, Elliott BC, et al. Changing sidestep cutting technique reduces knee valgus loading. Am J Sports Med 2009;37:2194-200.

27 Powers CM. The influence of abnormal hip mechanics on knee injury: a biomechanical perspective. J Orthop Sports Phys Ther 2010;40:42-51.

28 Sheehan FT, Sipprell WH, Boden BP. Dynamic sagittal plane trunk control during anterior cruciate ligament injury. Am I Sports Med 2012;40:1068-74.

29 Azubuike SO, Okojie OH. An epidemiological study of football (soccer) injuries in Benin City, Nigeria. Br J Sports Med 2009;43:382-6.

30 Woods C, Hawkins R, Hulse M, et al. The football association medical research programme: an audit of injuries in professional football-analysis of preseason injuries. Br J Sports Med 2002:36:436-41.

31 Benjaminse A, Webster KE, Kimp A, et al. Revised approach to the role of fatigue in anterior cruciate ligament injury prevention: a systematic review with meta-analyses. Sports Med 2019;49:565-86.

32 Bourne MN, Webster KE, Hewett TE. Is fatique a risk factor for anterior cruciate ligament rupture? Sports Med 2019;49:1629-35

33 Rahnama N, Reilly T, Lees A. Injury risk associated with playing actions during competitive soccer. Br J Sports Med 2002;36:354-9.

34 Krosshaug T, Nakamae A, Boden B, et al. Estimating 3D joint kinematics from video sequences of running and cutting maneuvers--assessing the accuracy of simple visual inspection. Gait Posture 2007;26:378-85. 